\title{
Superelectrophilic carbocations: preparation and reactions of a substrate with six ionizable groups
}

\author{
Sean H. Kennedy, Makafui Gasonoo and Douglas A. Klumpp*
}

\author{
Full Research Paper \\ Address: \\ Department of Chemistry and Biochemistry, Northern Illinois \\ University, DeKalb, IL 60178, USA \\ Email: \\ Douglas A. Klumpp* - dklumpp@niu.edu \\ * Corresponding author \\ Keywords: \\ cation; Friedel-Crafts; heterocycle; superacid; superelectrophile
}

Beilstein J. Org. Chem. 2019, 15, 1515-1520.

doi:10.3762/bjoc. 15.153

Received: 08 March 2019

Accepted: 21 June 2019

Published: 09 July 2019

This article is part of the thematic issue "Reactive intermediates carbocations".

Guest Editor: S. R. Hare

(C) 2019 Kennedy et al.; licensee Beilstein-Institut.

License and terms: see end of document.

\begin{abstract}
A substrate has been prepared having two triarylmethanol centers and four pyridine-type substituent groups. Upon ionization in the Brønsted superacid $\mathrm{CF}_{3} \mathrm{SO}_{3} \mathrm{H}$, the substrate undergoes two types of reactions. In the presence of only the superacid, the highly ionized intermediate(s) provide a double cyclization product having two pyrido[1,2-a]indole rings. With added benzene, an arylation product is obtained. A mechanism is proposed involving tetra-, penta-, or hexacationic species.
\end{abstract}

\section{Introduction}

During the 1970s and 80 s, Olah and co-workers described the novel chemistry of highly-charged organic cationic species. This work lead to the concept of superelectrophilic reactivity [1-5]. Examples of superelectrophiles include the nitronium dication (1) and the acetylium dication (2, Scheme 1). Both of these species have been proposed as superelectrophilic intermediates in the reactions of nitronium $\left(\mathrm{NO}_{2}{ }^{+}\right)$and acetylium $\left(\mathrm{CH}_{3} \mathrm{CO}^{+}\right)$salts in superacids. In sufficiently acidic media, cationic electrophiles such as the nitronium ion may undergo protonation, leading to the nitronium dication (1), and a greatly enhanced electrophilic reactivity. In superacidic solutions, nitronium salts have been shown to react with deactivated arenes and saturated hydrocarbons (including methane) [6-9].
Numerous studies from our group and others have shown that relatively stable cationic centers - such as ammonium, phosphonium, and pyridinium groups - may also be part of superelectrophilic systems [10]. Recently, we described the chemistry of tri-, tetra-, and pentacationic electrophiles based on the triarylmethyl cation scaffold (3-5, Scheme 1) [11,12]. These systems utilized pyridyl rings to produce increasing amounts of positive charge adjacent to the carbocation center. Both theoretical calculations and experimental results indicated that the carbocation center undergoes a high degree of delocalization into the neighboring phenyl group. Both the trication $\mathbf{3}$ and the tetracation 4 were directly observed from $\mathrm{FSO}_{3} \mathrm{H}-\mathrm{SbF}_{5}$ solution using low temperature NMR. Experimental observations 


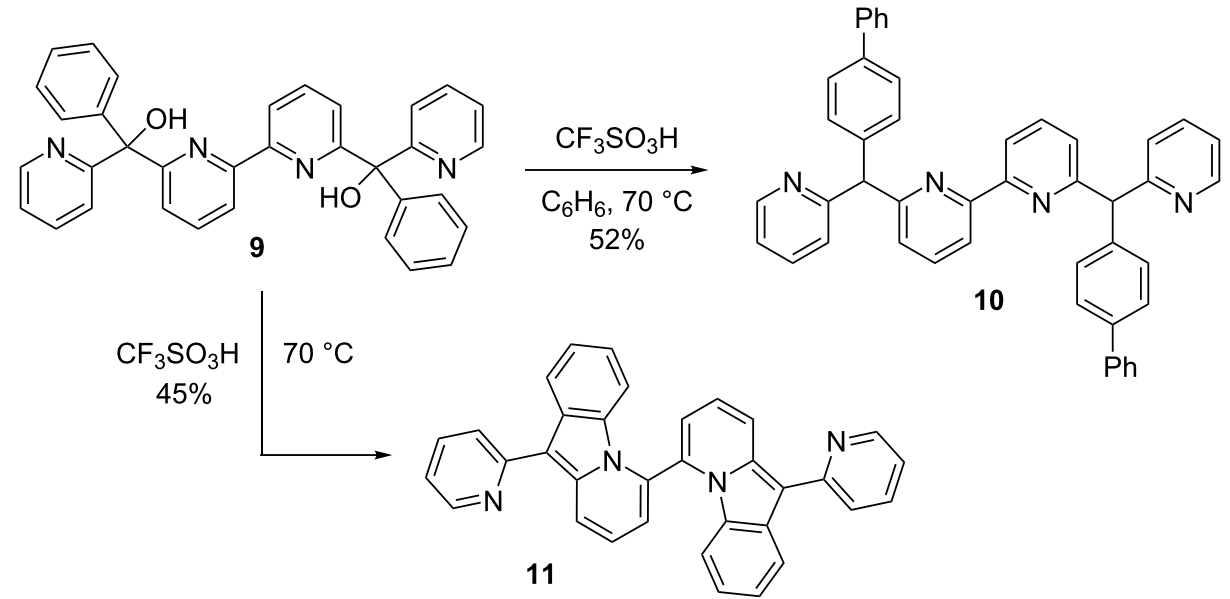

Scheme 3: Isolated yields of products from diol 9.

ionized intermediates:

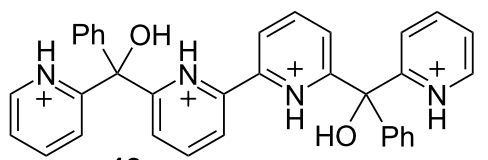

12

$\mathrm{H}^{+},-\mathrm{H}_{2} \mathrm{O}$

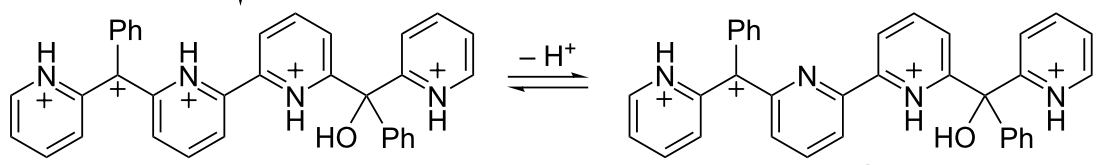

13

$\downarrow \mathrm{H}^{+},-\mathrm{H}_{2} \mathrm{O}$

15

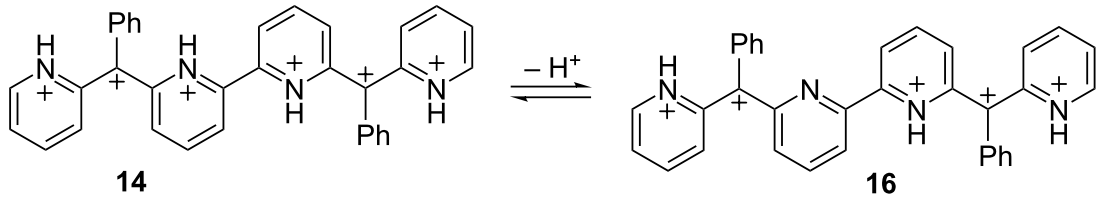

product formation:
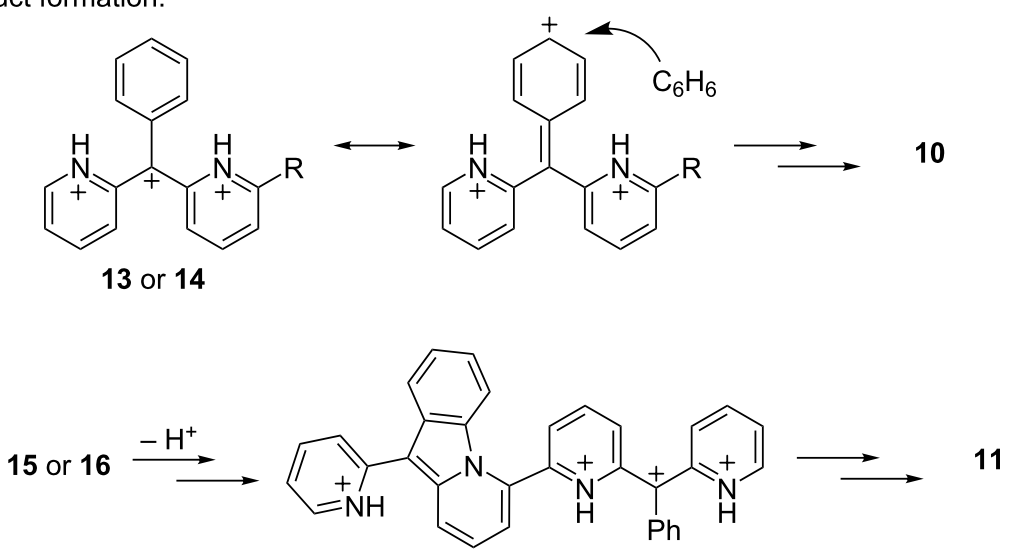

17

Scheme 4: Proposed mechanisms leading to products 10 and $\mathbf{1 1}$ 
tion and deprotonation of the para-carbon to complete the arylation step. For the cyclization product 11, theoretical calculations indicate that cyclization requires deprotonation at the pyridinium ring [11]. Thus, either the tetracation 15 or the pentacation $\mathbf{1 6}$ is the likely precursor to the pyrido[1,2-a]indole ring system. The conversion to product $\mathbf{1 1}$ also involves a stepwise process - initially forming compound $\mathbf{1 7}$ then a second cyclization gives the final product $\mathbf{1 1}$.

As noted above, no cyclization product $\mathbf{1 1}$ was observed when the chemistry was done in the presence of benzene. Only product $\mathbf{1 0}$ was obtained. This observation is in stark contrast to our earlier results involving both the tetracation 4 and pentacation 5. When these highly charged ions are generated in $\mathrm{CF}_{3} \mathrm{SO}_{3} \mathrm{H}$ and $\mathrm{C}_{6} \mathrm{H}_{6}$, significant quantities of the cyclization products are formed with the respective arylation products. For example, alcohol $\mathbf{1 8}$ provides a mixture of products $\mathbf{1 9}$ and $\mathbf{2 0}$ in a 32:68 ratio, presumably through the pentacation $\mathbf{5}$ (Scheme 5). Even with the use of the stronger Brønsted acid, $\mathrm{CF}_{3} \mathrm{SO}_{3} \mathrm{H}-\mathrm{SbF}_{5}$, significant quantities of the cyclization product $\mathbf{2 0}$ are observed. This raises an obvious question: why does substrate $\mathbf{9}$ provide exclusively the arylated product $\mathbf{1 0}$ in the presence of benzene, while substrate $\mathbf{1 8}$ leads to a significant proportion of cyclization product $\mathbf{2 0}$ ?
Our proposed mechanism of cyclization involves deprotonation of an $\mathrm{N}-\mathrm{H}$ bond at the pyridinium ring. Although pyridinium deprotonation is not generally expected in a Brønsted superacid, it can occur in these systems because of the large amount of cationic charge on these structures. In comparing the chemistry of compounds 9 and 18, compound 9 can lead to the hexacationic intermediate $\mathbf{1 4}$ while compound $\mathbf{1 8}$ can lead to the pentacationic intermediate 5. Examination of these two structures suggests that the phenyl groups have a profound effect on stabilizing the ions. Thus, the hexacationic system $\mathbf{1 4}$ is stabilized by two phenyl groups, while the pentacationic system $\mathbf{5}$ has one stabilizing phenyl group (Scheme 6). The ratio of charges is $2: 1$ (pyridinium/benzylic carbocation) for the hexacation 14, while the ratio of charges is $4: 1$ (pyridinium/benzylic carbocation) for the pentacation $\mathbf{5}$. Similarly, we previously reported good chemoselectivity for trication $\mathbf{3}$ - no cyclization product observed in the presence of benzene - but poor chemoselectivity for the tetracation 4 . The ratio of charges in these systems are consistent: a charge ratio of 2:1 shows good chemoselectivity (trication 3 ), while a charge ratio of 3:1 shows poor chemoselectivity (tetracation 4). As we previously reported, a reaction of tetracation 4 with benzene in $\mathrm{CF}_{3} \mathrm{SO}_{3} \mathrm{H}$ leads to a mixture of arylated product (52\%) and cyclization product $(48 \%)$. Thus, we observed clean arylation chemistry when the<smiles>OC(c1ccccc1)(c1cccc(-c2ccccn2)n1)c1cccc(-c2ccccn2)n1</smiles>

18<smiles>c1ccc(-c2cccc(C(c3ccc(-c4ccccn4)cc3)c3cccc(-c4ccccn4)n3)n2)cc1</smiles>

$19,32 \%$<smiles>c1ccc(-c2cccc(-c3c4ccccc4n4c(-c5ccccn5)cccc34)n2)nc1</smiles>

$20,68 \%$

Scheme 5: Products and relative yields from the reaction of alcohol 18 with $\mathrm{CF}_{3} \mathrm{SO}_{3} \mathrm{H}$ and $\mathrm{C}_{6} \mathrm{H}_{6}$ [12].

systems showing good chemoselectivity:

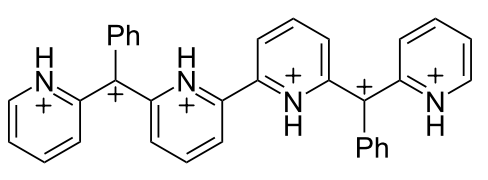

14<smiles>c1ccc(C(c2ccccn2)c2ccccn2)cc1</smiles>

3

systems showing poor chemoselectivity:<smiles>c1ccc([C+](c2ccccn2)c2cccc(-c3cccc[nH+]3)n2)cc1</smiles><smiles>C(=C(c1cccc(-c2cccc[nH+]2)n1)c1cccc(-c2ccccc2)[nH+]1)c1cccc[nH+]1</smiles>

5 
carbocation sites are flanked by not more than two pyridinium groups. This also means that increasing the number of adjacent pyridinium groups destabilizes the system as a whole and leads to greater $\mathrm{N}-\mathrm{H}$ deprotonation. Tetracation $\mathbf{4}$ and pentacation $\mathbf{5}$ tend to undergo $\mathrm{N}-\mathrm{H}$ deprotonation more readily, and consequently, this leads to rapid cyclization reactions.

Regarding the site of deprotonation, hexacation $\mathbf{1 4}$ could potentially undergo $\mathrm{N}-\mathrm{H}$ deprotonation at the inside pyridinium ring (16) or the outside pyridinium ring (21, Scheme 7). While inside deprotonation should give the observed cyclization product 11, outside deprotonation would give an entirely different product, one having the pyrido[1,2- $a$ ]indole ring at the end of the structure. Compound $\mathbf{1 1}$ is the only major product observed from the superacid-promoted reaction of diol $\mathbf{9}$. This suggests outside deprotonation - and formation of ion $\mathbf{2 1}$ - does not occur.

The preference for inside deprotonation may be understood to be a consequence of charge-charge repulsive effects. In the case of 21, the five cationic charges are on neighboring positions, while in the case of $\mathbf{1 6}$, the five cationic charges are separated into groups of three and two charges. The increased stability of the separated cationic charge is evident in the DFT calculated energies of the ions. At the B3LYP 6-311G (d,p) level, ion $\mathbf{1 6}$ is calculated to be $32.7 \mathrm{kcal} \cdot \mathrm{mol}^{-1}$ more stable than ion 21 [8]. Thus, highly charged organic ions may benefit by having groups of charges separated into smaller clusters rather than having all of the charges grouped together.

\section{Conclusion}

We have prepared a substrate with six ionizable sites. Reaction of the substrate in superacidic $\mathrm{CF}_{3} \mathrm{SO}_{3} \mathrm{H}$ leads to cyclization or arylation products, depending on the presence or absence of benzene. A mechanism is proposed involving tetra-, penta-, and hexacationic reactive intermediates. Most notably, this system shows remarkably good chemoselectivity in its reaction with benzene (only arylation product is observed). This is attributed to the presence of two carbocationic sites stabilized by benzylic-type resonance. Thus, molecular structures having a very large overall charge may be viable if stabilizing groups are incorporated into the structure.

\section{Experimental}

General. All reactions were performed using oven-dried glassware under an argon atmosphere. Trifluoromethanesulfonic acid (triflic acid) was freshly distilled prior to use. All commercially available compounds and solvents were used as received. ${ }^{1} \mathrm{H}$ and ${ }^{13} \mathrm{C}$ NMR were done using either $300 \mathrm{MHz}$ or $500 \mathrm{MHz}$ spectrometer; chemical shifts were made in reference to NMR solvent signals. Mass spectra were obtained from a commercial analytical laboratory. The synthesis of compound $\mathbf{9}$ is detailed in Supporting Information File 1.

Preparation of $6,6^{\prime}$-bis([1,1'-biphenyl]-4-yl(pyridin-2yl)methyl)-2,2'-bipyridine (10): In a pressure tube at $25^{\circ} \mathrm{C}$, compound 9 (52.2 $\mathrm{mg}, 0.10 \mathrm{mmol})$ was dissolved in benzene $(1 \mathrm{~mL}, 11.2 \mathrm{mmol})$, stirred for $5 \mathrm{~min}$ before triflic acid $(1 \mathrm{~mL}$, $11 \mathrm{mmol}$ ) was slowly added and the tube was then tightly closed. Following $24 \mathrm{~h}$ of stirring at $60-70{ }^{\circ} \mathrm{C}$, the reaction was cooled to room temperature, poured on about $10 \mathrm{~g}$ of ice and then neutralized with $10 \mathrm{M} \mathrm{NaOH}$ solution. The resulting aqueous solution was then partitioned between chloroform and distilled water in a separatory funnel. The aqueous fraction was subjected to two further extractions after which the organic fractions were combined, washed with brine, dried over anhydrous sodium sulfate and filtered. The solvent was removed by rotary evaporation and the product purified by column chromatography $\left(R_{\mathrm{f}} 0.21\right.$, hexane/ethyl acetate $\left.1: 1\right)$. Compound 10 was isolated in $52 \%$ yield as oil. ${ }^{1} \mathrm{H}$ NMR $\left(300 \mathrm{MHz}, \mathrm{CDCl}_{3}\right) \delta$ $5.85(\mathrm{~s}, 1 \mathrm{H}), 7.17-7.21(\mathrm{~m}, 1 \mathrm{H}), 7.30-7.51(\mathrm{~m}, 9 \mathrm{H}), 7.53-7.60$ $(\mathrm{m}, 4 \mathrm{H}), 7.64-7.70(\mathrm{~m}, 1 \mathrm{H}), 8.61(\mathrm{~d}, J=4.02 \mathrm{~Hz}, 1 \mathrm{H})$; ${ }^{13} \mathrm{C} \mathrm{NMR}\left(75 \mathrm{MHz}, \mathrm{CDCl}_{3}\right) \delta 60.7,121.9,123.1,124.3,126.1$, 127.1, 127.28, 127.33, 128.8, 129.6, 136.8, 138.8, 139.9, 140.2, 140.7, 141.4, 149.3, 161.1, 163.4; low-resolution ESIMS m/z: $643[\mathrm{M}+1], 553,477,475,401,324,323$; high-resolution CIMS $m / z$ : $[\mathrm{M}+1]$ calcd for $\mathrm{C}_{46} \mathrm{H}_{35} \mathrm{~N}_{4}, 643.2862$; found, 643.2856 .<smiles>c1ccc(C(c2ccccc2)c2cccc(-c3cccc([C+](c4ccccn4)c4ccccn4)n3)n2)cc1</smiles>

16

$\mathrm{E}+\mathrm{ZPE}$, hartrees relative energy, $\mathrm{kcal} / \mathrm{mol}$
1528.692949

0.0<smiles>c1ccc(-c2cccc(-c3cccc([C+](c4ccccn4)c4ccccn4)[nH+]3)[nH+]2)cc1</smiles>

21

1528.640854

$+32.7$ 
Preparation of $10,10^{\prime}$-di(pyridin-2-yl)-6,6'-bipyrido[1,2a]indole, (11): In a pressure tube at $25{ }^{\circ} \mathrm{C}$, compound 9 (200.1 mg, $0.481 \mathrm{mmol})$ was dissolved in triflic acid $(1 \mathrm{~mL}$, $11 \mathrm{mmol}$ ) and the tube was then tightly closed. Following $24 \mathrm{~h}$ of stirring at $60-70{ }^{\circ} \mathrm{C}$, the reaction was cooled to room temperature, poured on about $10 \mathrm{~g}$ of ice and then neutralized with $10 \mathrm{M} \mathrm{NaOH}$ solution. The resulting aqueous solution was then partitioned between chloroform and distilled water in a separatory funnel. The aqueous fraction was subjected to two further extractions after which the organic fractions were combined, washed with brine, dried over anhydrous sodium sulfate and filtered. The solvent was removed by rotary evaporation and the product purified by column chromatography $\left(R_{\mathrm{f}} 0.30\right.$, hexane/ ethyl acetate $1: 1)$. The product $\mathbf{1 1}$ was isolated in $45 \%$ yield as brown oil. ${ }^{1} \mathrm{H}$ NMR $\left(300 \mathrm{MHz}, \mathrm{CDCl}_{3}\right) \delta 6.81-6.88(\mathrm{~m}, 2 \mathrm{H})$, $7.19(\mathrm{t}, J=4.65 \mathrm{~Hz}, 1 \mathrm{H}), 7.35-7.40(\mathrm{~m}, 1 \mathrm{H}), 7.51(\mathrm{t}, J=$ $7.50 \mathrm{~Hz}, 1 \mathrm{H}), 7.75-7.82(\mathrm{~m}, 2 \mathrm{H}), 8.24-8.29(\mathrm{~m}, 2 \mathrm{H}), 8.81(\mathrm{~d}$, $J=2.55 \mathrm{~Hz}, 1 \mathrm{H}), 9.15(\mathrm{~d}, J=8.79 \mathrm{~Hz}, 1 \mathrm{H}) ;{ }^{13} \mathrm{C} \mathrm{NMR}$ $\left(75 \mathrm{MHz}, \mathrm{CDCl}_{3}\right) \delta 107.2,116.0,116.1,116.7,118.1,119.2$, 120.20, 120.28, 123.3, 123.6, 124.2, 128.3, 131.9, 136.4, 138.1, 149.7, 154.4; low-resolution ESIMS m/z: 487 [M + 1], 397, 353, 320, 319, 279, 244; high-resolution CIMS $m / z$ : [M + 1], calcd for $\mathrm{C}_{34} \mathrm{H}_{23} \mathrm{~N}_{4}, 487.1923$; found, 487.1917.

\section{Supporting Information}

\section{Supporting Information File 1}

Experimental procedures, compounds characterization, and NMR spectra; computational methods and results. [https://www.beilstein-journals.org/bjoc/content/ supplementary/1860-5397-15-153-S1.pdf]

\section{Acknowledgements}

This work was supported by the National Science Foundation (1300878). We gratefully acknowledge this support.

\section{ORCID ${ }^{\circledR}$ iDs}

Douglas A. Klumpp - https://orcid.org/0000-0001-5271-699X

\section{References}

1. Olah, G. A.; Germain, A.; Lin, H. C.; Forsyth, D. A. J. Am. Chem. Soc. 1975, 97, 2928-2929. doi:10.1021/ja00843a067

2. Olah, G. A.; Prakash, G. K. S.; Donald, P.; Loker, K. B.; Lammertsma, K. Res. Chem. Intermed. 1989, 12, 141-159. doi:10.1163/156856789x00104

3. Olah, G. A. Angew. Chem., Int. Ed. Engl. 1993, 32, 767-788. doi:10.1002/anie.199307673

4. Olah, G. A.; Klumpp, D. A. Acc. Chem. Res. 2004, 37, 211-220. doi:10.1021/ar020102p
5. Olah, G. A.; Klumpp, D. A. Superelectrophiles and Their Chemistry; John Wiley and Sons: Hoboken, NJ, 2008. doi:10.1002/9780470185124

6. Olah, G. A.; Lin, H. C. J. Am. Chem. Soc. 1974, 96, 549-553. doi:10.1021/ja00809a035

7. Olah, G. A.; Lin, H. C. Synthesis 1974, 444-445. doi:10.1055/s-1974-23344

8. Olah, G. A.; Orlinkov, A.; Oxyzoglou, A. B.; Prakash, G. K. S. J. Org. Chem. 1995, 60, 7348-7350. doi:10.1021/jo00127a048

9. Olah, G. A.; Wang, Q.; Orlinkov, A.; Ramaiah, P. J. Org. Chem. 1993, 58, 5017-5018. doi:10.1021/jo00070a049

10. Klumpp, D. A. Activation of Electrophilic Sites by Adjacent Cationic Groups. In Recent Developments in Carbocation and Onium Ion Chemistry; Laali, K., Ed.; ACS Symposium Series 395; American Chemical Society: Washington, DC, 2007; pp 144-159. doi:10.1021/bk-2007-0965.ch008

11. Naredla, R. R.; Zheng, C.; Nilsson Lill, S. O.; Klumpp, D. A. J. Am. Chem. Soc. 2011, 133, 13169-13175. doi:10.1021/ja2046364 12. Gasonoo, M.; Naredla, R. R.; Nilsson Lill, S. O.; Klumpp, D. A. J. Org. Chem. 2016, 81, 11758-11765. doi:10.1021/acs.joc.6b02220 13. Newkome, G. R.; Joo, Y. J.; Evans, D. W.; Pappalardo, S.; Fronczek, F. R. J. Org. Chem. 1988, 53, 786-790. doi:10.1021/jo00239a018

14. Gaussian 09, Revision E.01; Gaussian, Inc.: Wallingford, CT, 2009.

\section{License and Terms}

This is an Open Access article under the terms of the Creative Commons Attribution License (http://creativecommons.org/licenses/by/4.0). Please note that the reuse, redistribution and reproduction in particular requires that the authors and source are credited.

The license is subject to the Beilstein Journal of Organic Chemistry terms and conditions: (https://www.beilstein-journals.org/bjoc)

The definitive version of this article is the electronic one which can be found at: doi:10.3762/bjoc. 15.153 